\title{
Fatty Acid Esters of Triterpenes from Erythroxylum passerinum
}

\author{
Marizeth L. Barreiros ${ }^{a}$, Jorge M. David ${ }^{a}$, Pedro A. de P. Pereira ${ }^{a}$, Maria L. S. Guedes ${ }^{b}$ and \\ Juceni P. David ${ }^{*, c}$ \\ ${ }^{a}$ Instituto de Química, ${ }^{b}$ Instituto de Biologia, ${ }^{c}$ Faculdade de Farmácia, Universidade Federal da Bahia, \\ Campus de Ondina, 40170-290 Salvador-BA, Brazil
}

\begin{abstract}
O extrato hexânico das folhas de Erythroxylum passerinum além de sitosterol, $\beta$-amirina, lupeol e eritrodiol, forneceu palmitato de $\beta$-amirina, palmitato de $3 \beta, 28$-diidroxi-olean-12-enila (eritrodiol); palmitato de $3 \beta, 11 \beta$-diidroxi-olean-12-enila; palmitato de $3 \beta$-hidroxi-11-oxo-olean-12-enila e palmitato de $3 \beta$-hidroxi-11,12-epoxi-friedoolean-14-enila. As estruturas das substâncias foram estabelecidas através da análise dos seus dados espectrométricos, bem como de seus derivados transesterificados, utilizando-se técnicas de $\mathrm{RMN}$ de ${ }^{1} \mathrm{H}$ e de ${ }^{13} \mathrm{C}$, infravermelho e espectrometria de massas.
\end{abstract}

The hexane extract of leaves of Erythroxylum passerinum yielded besides sitosterol, $\beta$-amyrin, lupeol and erythrodiol, $\beta$-amyrin palmitate, $3 \beta$,28-dihydroxy-olean-12-enyl palmitate, $3 \beta, 11 \beta$ dihydroxy-olean-12-enyl palmitate, $3 \beta$-hydroxy-11-oxo-olean-12-enyl palmitate and $3 \beta$-hydroxy11,12-epoxy-friedoolean-14-enyl palmitate. The structural elucidation of the isolates and of their derivatives were based on spectral data $\left({ }^{1} \mathrm{H}\right.$ and ${ }^{13} \mathrm{C}$ NMR, IR and MS).

Keywords: Erythroxylum passerinum, Erythroxylaceae, fatty acid esters of triterpenes

\section{Introduction}

The genus Erythroxylum is the largest of the Erythroxylaceae family embracing $97 \%$ of its species, which are mainly spread through tropical and subtropical regions. ${ }^{1,2}$ Many wild and endemic species of this genus, occur in the Bahia State, mostly along the coast in Restinga and the Restinga forest on sandy soils. ${ }^{3}$ The occurrence of species in both Restinga and moist tropical forests soil is also common. ${ }^{3,4}$

The chemical composition of this genus is formed basically by alkaloids and terpenes, especially triterpenes which are found in leaves and fruits of its species. ${ }^{2}$ The presence of fatty acids esterified with triterpenes in leaves has been a common characteristic of species that occur in the Brazilian Restinga. ${ }^{4}$

The present work describes the isolation of $\beta$-sitosterol, lupeol, $\beta$-amyrin, erythrodiol and of fatty acids esterified with triterpenes at the C-3 position (1-5). The following compounds were isolated and are described below: $\beta$ amyril palmitate (1), 3 $\beta$-hydroxy-11-oxo-olean-12-enyl

*e-mail: juceni@ufba.br palmitate (2a), 3 $\beta, 11 \beta$-dihydroxy-olean-12-enyl palmitate (3), 3 $\beta$,28-dihydroxy-olean-12-enyl palmitate (4) and $3 \beta$ hydroxy-11,12-epoxy-friedoolean-14-enyl palmitate (5).

\section{Results and Discussion}

The structural elucidation of fatty acids esterified with triterpenes by NMR is only possible by analyses of ${ }^{13} \mathrm{C}$ data (PND and DEPT experiments). The ${ }^{1} \mathrm{H}$ NMR spectrum is not informative due to the predominance of the peak of methylene groups of the fatty acids. However, the triterpene moieties of these compounds can be preliminary checked by TLC employing the Lieberman-Burchard spray reagent as the developer. Otherwise the nature of the fatty acid contents can be identified by GC/MS analyses of their methyl esters produced through transesterification reactions.

The ${ }^{13} \mathrm{C}$ NMR spectra of compounds 1-4 showed methine and quartenary $C s p^{2}$ signals $(\delta 121.9 \pm 0.3$ and $144.6 \pm 0.5$ ) characteristic of oleanene triterpenes. ${ }^{5}$ Detailed analyses of these spectra indicated that all triterpene moieties were esterified with fatty acids. This observation was supported by the presence in the spectra of all compounds of peaks of an additional methyl $(\delta 13.97 \pm$ 0.06) and of acyl groups (ca. $\delta$ 173.4) whose carbonyls 


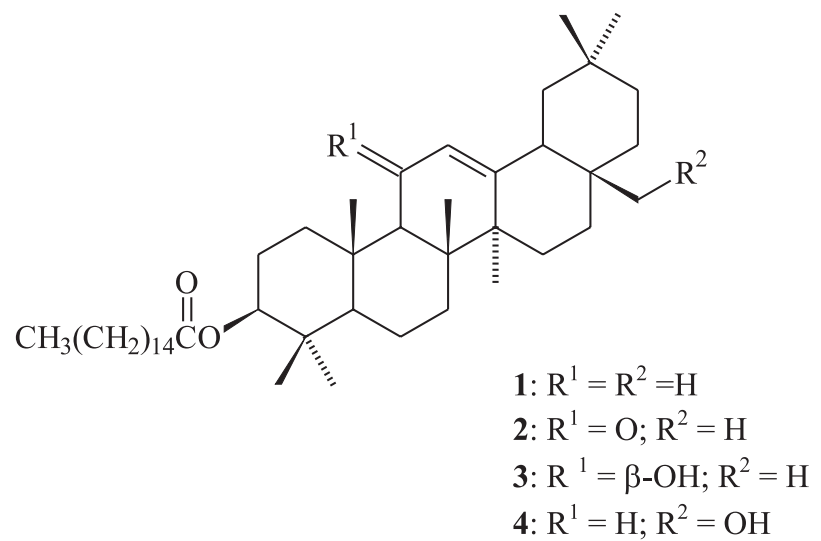

were downshielded ( $\Delta \delta c a .3 .2)$ relative to $3 \beta$-acetylamyrin. Comparison of the chemical shifts observed for the carbonyl carbons in the fatty acid moiety in these compounds with those found for $3 \beta$-acetyl-amyrin showed ca. 3 ppm downshield. The $\mathrm{C}-2$ of the triterpene moieties in these compounds were shielded ( $\Delta \delta 4 \mathrm{ppm})$, while the oxy methine carbons showed downshielding effect in comparison to $\mathrm{C}-3$ of $\beta$-amyrin. ${ }^{5}$ In addition, the $\mathrm{C}$ - 3 signals of these triterpenes appeared at higher frequency $(\delta 80.5 \pm$ $0.05 \mathrm{ppm}$ ) than that observed for $\beta$-amyrin ( $\delta$ 78.9). The molecular ions recorded on the MS at $m / z 678$ (2), $m / z 662$ (3) and $m / z 662$ (4) were conclusive of the esterified nature of the triterpenes.

The identification of the triterpene moiety of $\mathbf{1}$ as being $\beta$-amyrin was possible by direct comparison of the NMR data of 1 with the data reported in the literature. ${ }^{5}$ Transesterification of this compound yielded $\beta$-amyrin and methyl palmitate $(m / z, 270)$ which were characterized by $\mathrm{GC}$ analysis.

The ${ }^{13} \mathrm{C}$ NMR spectra (PND and DEPT) of compound 2 displayed characteristic signals for a $\alpha, \beta$-unsaturated ketone group at $\delta 200.2,128.1$ and 170.6. The presence of this group was corroborated by the ${ }^{1} \mathrm{H}$ NMR spectrum which displayed a singlet at $\delta 5.59$ attributed to the $\alpha$-carbonyl hydrogen (H-12). In addition, this assignment was confirmed by the presence of a signal at $\delta 2.36$ due to H-9 in agreement with the methine signal at $\delta 61.7$ displayed for $\mathrm{C}-9$ in the ${ }^{13} \mathrm{C}$ NMR spectrum. In the ${ }^{1} \mathrm{H}$ NMR spectrum it was also possible to observe a multiplet signal at $\delta 4.50$ due to $\mathrm{H}-3$ bonded to the esterified carbon.

The mass spectrum of the transesterification product of 2 made it possible to recognize the palmitic acid esterified at the $\mathrm{C}-3$ position of the triterpene through the methyl palmitate $(\mathrm{m} / \mathrm{z}, 270)$. Besides, comparison of the ${ }^{13} \mathrm{C}$ NMR data (Table) with those found in the literature for $3 \beta, 28$-dihydroxy-11-oxo-olean-12-ene ${ }^{6}$ allowed the identification of the structure of the triterpene moiety as being $3 \beta$-hydroxy-11-oxo-olean-12-ene.

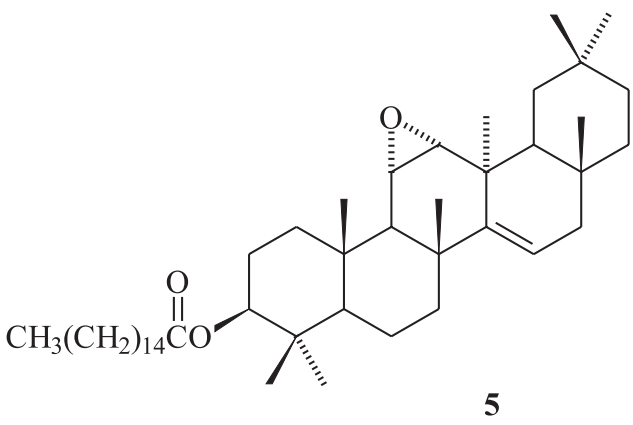

The ${ }^{1} \mathrm{H}$ NMR spectrum of $\mathbf{3}$ showed the $\mathrm{H}-12$ signal as a doublet at $\delta 5.24(\mathrm{~d}, J 3.7 \mathrm{~Hz})$ whose multiplicity and position indicated that $\mathrm{C}-11$ was a methine carbon. Thus the signal at $\delta 4.18(\mathrm{dd}, J 3.7$ and $7.9 \mathrm{~Hz}$ ) was due to the hidroxy methine H-11. The ${ }^{13} \mathrm{C}$ NMR spectra (PND and DEPT $135^{\circ}$ ) corroborated the previous statements through the peaks displayed at $\delta 67.7,125.4$ and 149.4. The observation of the additional oxy methine carbon peak at $\delta 67.7$ and comparison of the ${ }^{1} \mathrm{H}$ and ${ }^{13} \mathrm{C}$ NMR data of this compound with the data described for $3 \beta, 11 \alpha$ dihydroxy-olean-12-ene ${ }^{5,7}$ (Table 1) allowed to establish the $\beta$ relative stereochemistry for the hydroxy group at $\mathrm{C}$ 11 in compound 3 . The $\mathrm{H}-11$ peak of $3 \beta, 11 \alpha$-dihydroxyolean-12-ene appeared at $\delta 4.50(\mathrm{dd}, J 3.6 \text { and } 9.0 \mathrm{~Hz})^{5}$ while in 3 it appeared at $\delta 4.18(\mathrm{dd}, J 3.7$ and $7.9 \mathrm{~Hz})$. Similarly, the chemical shift observed for the C-11 of $3 \beta, 11 \alpha$-dihydroxy-olean-12-ene ( $\delta 81.7)$ appears at higher frequency than for the $11 \beta$-derivative $(\delta 67.7)$. The deshielding effects of C-12 ( $\delta$ 125.4) and C-9 $(\delta 56.3)$ of $\mathbf{3}$ when compared with the values observed for $3 \beta, 11 \alpha$ dihydroxy-olean-12-ene ( $\delta 121.1$ and 49.7, respectively) could be explained by the different distances between $\mathrm{H} /$ $\mathrm{C}-9$ and the pseudo-axial $\mathrm{OH}$ group in $\mathrm{C}-11$. In compound 3 this group is closer to C-9 and C-12 than in the 11- $\alpha$ derivative. This statement is in agreement with the chemical shift of C-9 ( $\delta$ 51.6) of the $11 \alpha$-methoxy derivative. ${ }^{8}$ The mass spectrum recorded for the transesterification product of $\mathbf{3}$ made it possible to recognize palmitic acid esterified at the $\mathrm{C}-3$ position of the triterpene through the molecular ion at $\mathrm{m} / \mathrm{z} 270$ (methyl palmitate).

The triterpene moiety of compound $\mathbf{4}$ was also characterized by ${ }^{13} \mathrm{C}$ NMR spectral data of fatty acid ester. By comparison with the ${ }^{13} \mathrm{C}$ NMR data of $\beta$-amyrin and erythrodiol $^{5}$ the absence of a methyl peak (C-28) at $\delta 28.4$ and the presence of an oxy methylene carbon at $\delta 69.7$ were noted. These considerations made it possible to place this additional hydroxyl group at C-28. The mass spectrum of 
Table 1. ${ }^{13} \mathrm{C}$ NMR spectral data for the fatty acid esters of triterpenes $\mathbf{2}, \mathbf{3}$ and $\mathbf{5}\left[75 \mathrm{MHz}, \mathrm{CDCl}_{3}, \delta\right.$ (ppm)]

\begin{tabular}{|c|c|c|c|c|c|c|c|}
\hline $\mathrm{C}$ & 2 & $\begin{array}{c}3 \beta, 28- \\
\text { dihydroxy-11-oxo- } \\
\text { olean-12-ene }\end{array}$ & 3 & $\begin{array}{c}3 \beta, 11 \alpha- \\
\text { dihydroxy- } \\
\text { olean-12-ene }\end{array}$ & $\begin{array}{l}3 \beta \text {-hydroxy- } \\
11 \alpha \text {-methoxy- } \\
\text { olean-12-ene }\end{array}$ & 5 & $\begin{array}{c}\text { 11,12-epoxy- } \\
\text { friedoolean- } \\
\text { 14-ene }{ }^{9}\end{array}$ \\
\hline 1 & 38.8 & 39.2 & 40.1 & 39.5 & 39.26 & 37.9 & 37.92 \\
\hline 2 & 23.6 & 27.3 & 23.7 & 27.4 & 27.30 & 23.2 & 23.27 \\
\hline 3 & 80.3 & 78.8 & 80.4 & 78.7 & 78.61 & 80.7 & 80.30 \\
\hline 4 & 38.1 & 39.2 & 38.7 & 39.0 & 39.00 & 37.6 & 37.69 \\
\hline 5 & 55.0 & 55.0 & 55.3 & 55.1 & 55.02 & 54.6 & 54.59 \\
\hline 6 & 17.4 & 17.5 & 18.3 & 18.4 & 18.24 & 18.2 & 18.74 \\
\hline 7 & 32.7 & 32.7 & 33.1 & 32.9 & 33.08 & 33.2 & 33.18 \\
\hline 8 & 43.4 & 45.4 & 43.4 & 43.3 & 43.05 & 39.0 & 38.94 \\
\hline 9 & 61.7 & 61.8 & 56.3 & 49.7 & 51.56 & 51.8 & 51.83 \\
\hline 10 & 37.0 & 37.0 & 38.0 & 37.9 & 38.56 & 37.5 & 37.53 \\
\hline 11 & 200.2 & 200.1 & 67.7 & 81.7 & 75.85 & 53.5 & 53.49 \\
\hline 12 & 128.1 & 128.3 & 125.4 & 121.2 & 121.51 & 58.2 & 58.17 \\
\hline 13 & 170.6 & 169.4 & 149.4 & 153.2 & 149.67 & 36.6 & 36.55 \\
\hline 14 & 45.4 & 43.4 & 41.8 & 41.8 & 41.70 & 157.1 & 157.13 \\
\hline 15 & 26.4 & 25.8 & 25.2 & 26.4 & 26.13 & 118.9 & 118.90 \\
\hline 16 & 26.5 & 21.6 & 26.7 & 27.4 & 26.60 & 35.2 & 35.25 \\
\hline 17 & 32.4 & 37.1 & 33.2 & 32.3 & 32.30 & 35.4 & 35.37 \\
\hline 18 & 47.6 & 42.7 & 46.5 & 46.9 & 46.76 & 48.1 & 48.15 \\
\hline 19 & 45.2 & 44.9 & 46.5 & 46.9 & 46.36 & 40.3 & 40.29 \\
\hline 20 & 31.1 & 31.1 & 31.1 & 31.2 & 31.07 & 28.7 & 30.16 \\
\hline 21 & 34.9 & 32.9 & 34.9 & 34.7 & 34.51 & 36.6 & 36.54 \\
\hline 22 & 36.5 & 30.1 & 37.0 & 37.0 & 36.84 & 38.2 & 38.12 \\
\hline 23 & 28.1 & 28.1 & 28.1 & 28.0 & 28.03 & 27.9 & 27.92 \\
\hline 24 & 16.4 & 15.6 & 16.7 & 15.5 & 15.44 & 17.0 & 16.99 \\
\hline 25 & 16.8 & 16.4 & 18.1 & 18.3 & 18.04 & 16.6 & 16.66 \\
\hline 26 & 18.7 & 18.6 & 16.9 & 16.8 & 16.76 & 27.0 & 27.02 \\
\hline 27 & 23.4 & 23.4 & 26.2 & 24.7 & 25.07 & 30.2 & 30.23 \\
\hline 28 & 28.8 & 69.7 & 28.5 & 28.5 & 28.35 & 29.8 & 29.92 \\
\hline 29 & 33.1 & 32.9 & 33.2 & 33.3 & 33.11 & 33.7 & 33.62 \\
\hline 30 & 23.5 & 23.4 & 23.6 & 23.7 & 23.52 & 19.5 & 19.52 \\
\hline -COO- & 173.7 & - & 173.6 & - & & 174.5 & - \\
\hline $\mathrm{H}_{3} \mathrm{CCO}-$ & 14.1 & - & 14.1 & - & & 14.1 & \\
\hline $\mathrm{OCH}_{3}$ & & & & & 53.67 & & \\
\hline
\end{tabular}

the product from the transesterification of $\mathbf{4}$ confirmed the structure of the triterpene moiety as $3 \beta$-28-dihydroxy-olean12-ene $(\mathrm{m} / \mathrm{z}$ 442).

Detailed analyses of the ${ }^{13} \mathrm{C}$ NMR data of 5 pointed out that it also was esterified with a fatty acid. The MS exhibited a molecular ion at $\mathrm{m} / \mathrm{z} 678$ corroborating with this statement. Analyses of the ${ }^{13} \mathrm{C}$ NMR spectra (PND and DEPT $135^{\circ}$ ) of compound $\mathbf{5}$ made it possible to recognize signals at $\delta 118.9$ and 157.1 and signals for methyl groups which were very close to the values found for a taraxarene skeleton (or friedoolean-14-ene). However the presence of signals due to two methyne carbons, at $\delta 53.5$ and 58.2, both deshielded in comparison with the methyne groups of taraxerol ${ }^{5}$, and the absence of two methylene groups suggested the presence of an epoxy group at the C-11 and $\mathrm{C}-12$ positions. Besides, the downshielded methyne group at $\delta 51.8(\mathrm{C}-9)$ and the upshielded quaternary carbons at $\delta$ $36.6(\mathrm{C}-13)$ and $\delta 48.2(\mathrm{C}-18)$ in comparison with $\mathrm{C}-9(\delta$ $48.9)$ and $\mathrm{C}-13(\delta 37.9)$ of taraxerol confirmed the presence of an oxirane group in that position. These data were confirmed by the ${ }^{1} \mathrm{H}$ NMR spectrum that exhibited absorptions at $\delta 2.80(\mathrm{~d}, J 4.8 \mathrm{~Hz}, \mathrm{H}-12), 3.11(\mathrm{t}, J 4.8 \mathrm{~Hz}$, $\mathrm{H}-11$ ), 5.55 (dd, $J 3.3$ and $7.9 \mathrm{~Hz}, \mathrm{H}-15)$ and at $\delta 4.52$ (dd, $J 4.8$ and $11.0 \mathrm{~Hz}$ ) observed for the oxy methyne C-3. The latter signal was characteristic of esterification at this position. Comparison of these data with those found in the literature for taraxerol and for the acetyl derivative of $11 \alpha, 12 \alpha$-epoxy-taraxerol ${ }^{9}$ allowed to identify the triterpene moiety as being $3 \beta$-hydroxy- $11 \alpha, 12 \alpha$-epoxyfriedoolean-14-ene (Table 1). The mass spectrum of the product from the transesterification of pure $\mathbf{5}$ also made it possible to recognize palmitic acid esterified at the C-3 of the triterpene.

This is the first time that fatty acid esters of the triterpenes 2, 3 and $\mathbf{5}$ are reported in the literature. Although the triterpene moiety $3 \beta, 11 \beta$-dihydroxy-olean-12-ene (3) has been obtained through synthesis ${ }^{10,11}$ this is the first report of its isolation from a natural source. A significant 
number of plant species in different families contain fatty acids esterified with triterpenes or steroids, usually as a mixture of fatty acids, ${ }^{12,13}$ however, previous studies of Erythroxylum also showed only palmitates. ${ }^{4}$

\section{Experimental}

GC/MS analyses were carried out in a GC chromatograph Varian mod. Saturn II coupled to an ion trap mass detector, employing a DB1-MS column (30 m x $0.32 \mathrm{~mm} \times 1 \mu \mathrm{m})$. Mass spectra by direct injection $(70 \mathrm{eV})$ of the esterified triterpenes were obtained on a HP mass selective detector equipment Mod. 5973. NMR spectra were recorded on a Varian Gemini 300 equipment using $\mathrm{CDCl}_{3}$ as solvent and assigning the residual solvent signal as internal reference. Infrared spectra were recorded on a JASCO mod. Valor III spectrophotometer.

Botanical material was collected at the restinga of Reserva do Parque da Lagoa do Abaeté, in the vicinity of Salvador- BA (Brazil). Identification of the plant species was carried out by Prof. Maria Lenise S. Guedes. A voucher is deposited at Herbarium Alexandre Leal Costa of Biology Institute of Federal University of Bahia, under number 24280 .

\section{Isolation of the constituents}

The dried leaves of E. passerinum (2.6 kg) were extracted with $\mathrm{MeOH}$. The crude extract (93.4 g) was filtered over $\mathrm{SiO}_{2}$ using hexane, hexane/EtOAc (8:2) and EtOAc as solvent systems. These procedures furnished residues $\mathrm{A}$ (1.1 g), B (1.21 g) and C (2.06 g), respectively. Residue B was submitted to $\mathrm{CC}$ on $\mathrm{SiO}_{2}$ eluted with hexane/EtOAc (98:2). The fractions were grouped and sequentially submitted to purification through $\mathrm{CC}$ on $\mathrm{SiO}_{2}$ using ether/ petrol mixtures. The fraction eluted with ether/petrol 95:5 gave compound $2(5.6 \mathrm{mg})$ while from the fractions eluted with a 98:2, 9:1 and 8:2 mixtures, $\beta$-amyril palmitate (1), compound 5 (13.5 mg) and $\mathbf{3}(17.8 \mathrm{mg})$ were obtained, respectively. Residue $\mathrm{C}$, after purification through $\mathrm{CC}$ on $\mathrm{SiO}_{2}$ eluted with hexane/EtOAc 95:5, followed by preparative TLC (hexane/EtOAc 9:1), furnished lupeol, $\beta$ amyrin, erythrodiol and erythrodiolyl palmitate or $3 \beta, 28$ dihydroxy-olean-12-enyl palmitate (4) besides sitosterol.

Transesterification of fatty acid esters of triterpenes. The esters of $\mathbf{1}$ - $\mathbf{5}$ were respectively refluxed in dry $\mathrm{MeOH}$ $(20 \mathrm{~mL})$ with sodium methoxide $(20 \mathrm{mg})$ for $1 \mathrm{~h}$. The reaction product was extracted with $\mathrm{H}_{2} \mathrm{O}$ and $\mathrm{CH}_{2} \mathrm{Cl}_{2}$. The organic phase was separated, dried over $\mathrm{Na}_{2} \mathrm{SO}_{4}$ and evapored. From the esters of compounds $\mathbf{1}-\mathbf{5}$ the respective methyl esters of palmitic acid were obtained
(43.8 mg, $2.3 \mathrm{mg}, 8.3 \mathrm{mg}, 3.2 \mathrm{mg}$ and $7.6 \mathrm{mg}$ ). Addition of $\mathrm{HCl}(1 \%)$ to the remaining aqueous phase, followed by extraction with $\mathrm{CH}_{2} \mathrm{Cl}_{2}$ yielded the triterpene moieties $\beta$ amyrin (1); $3 \beta$-hydroxy-11-oxo-olean-12-ene (2); $3 \beta, 11 \beta$ dihydroxy-olean-12-ene (3); erythrodiol (4) and $3 \beta$ hydroxy-11,12-epoxy-friedoolean-14-ene. (5).

$\beta$-Amyrin palmitate (1). White wax. $[\alpha]_{\mathrm{D}}^{25}+26.3^{\circ}(c 4.0$ hexane); ${ }^{13} \mathrm{C} \mathrm{NMR}\left(\mathrm{CDCl}_{3}\right): \delta 38.2(\mathrm{C}-1), 22.7(\mathrm{C}-2), 80.6$ (C-3), 37.7 (C-4), 55.2 (C-5), 18.2 (C-6), 32.8 (C-7), 39.7 (C-8), 47.1 (C-9), 36.9 (C-10), 23.5 (C-11), 121.6 (C-12), 145.0 (C-13), 41.6 (C-14), 26.8 (C-15), 26.0 (C-16), 32.3 (C-17), 47.8 (C-18), 47.4 (C-19), 31.1 (C-20), 35.6 (C-21), 37.1 (C-22), 28.4 (C-23), 16.6 (C-24), 15.6 (C-25), 16.8 (C-26), 25.9 (C-27), 28.0 (C-28), 33.4 (C-29), 23.6 (C-30), $173.6(\mathrm{COO}), 14.1\left(\mathrm{CH}_{3}\right), 29.6\left(\mathrm{CH}_{2}\right)_{n}$.

3 $\beta$-Hydroxy-11-oxo-olean-12-enyl palmitate (2). White wax. $[\alpha]_{\mathrm{D}}^{25}+28.0^{\circ}\left(c 3.0 \mathrm{CHCl}_{3}\right)$; $\mathrm{MS}(\mathrm{m} / \mathrm{z}): 678(8$, $\mathrm{C}_{46} \mathrm{H}_{78} \mathrm{O}_{2}$ ), 423 (16), 273 (100), 232 (87); ${ }^{13} \mathrm{C}$ NMR $\left(\mathrm{CDCl}_{3}\right)$ : Table. ${ }^{1} \mathrm{H} \mathrm{NMR}\left(300 \mathrm{MHz}, \mathrm{CDCl}_{3}\right): \delta 5.59(\mathrm{~s}, \mathrm{H}-$ 12); 4.50 (dd, H-3); 1.35 (s, $\mathrm{CH}_{3}$ ); 1.16 (s, $\left.\mathrm{CH}_{3}\right) ; 1.13$ (s, $\left.\mathrm{CH}_{3}\right), 0.90\left(\mathrm{~s}, 4 \times \mathrm{CH}_{3}\right)$ and $0.83\left(\mathrm{~s}, \mathrm{CH}_{3}\right) . \mathrm{IR} v_{\max } / \mathrm{cm}^{-1}$ : 2926, 2855, 1735 (COO), 1665 (C=O) (film).

$3 \beta, 11 \beta$-dihydroxy-olean-12-enyl palmitate (3). White wax. $[\alpha]_{\mathrm{D}}^{25}+45.0^{\circ}\left(c 4.3 \mathrm{CHCl}_{3}\right) ; \mathrm{MS}(\mathrm{m} / \mathrm{z}): 662\left(38, \mathrm{C}_{46} \mathrm{H}_{80} \mathrm{O}_{2}\right.$ - $\mathrm{H}_{2} \mathrm{O}$ ), 407 (19), 255 (45), 234 (35), 218 (58), 203 (49), 189 (35); ${ }^{13} \mathrm{C}$ NMR $\left(\mathrm{CDCl}_{3}\right)$ : Table; ${ }^{1} \mathrm{H}$ NMR $(300 \mathrm{MHz}$, $\left.\mathrm{CDCl}_{3}\right): \delta 5.24(\mathrm{~d}, J 3.7 \mathrm{~Hz}, \mathrm{H}-12) ; 4.50$ (m, H-3), $4.18(\mathrm{dd}$, J 7.9 and $3.7 \mathrm{~Hz}) ;$ ); $1.22\left(\mathrm{~s}, \mathrm{CH}_{3}\right) ; 1.09\left(\mathrm{~s}, \mathrm{CH}_{3}\right) ; 1.01$ (s, $\left.\mathrm{CH}_{3}\right), 0.88\left(\mathrm{~s}, 4 \mathrm{CH}_{3}\right)$ and $0.84\left(\mathrm{~s}, \mathrm{CH}_{3}\right) . \mathrm{IR} v_{\max } / \mathrm{cm}^{-1}: 3437$ (HO), 2926, 2855, 1732 (COO) (film).

Erythrodiol or 3 $\beta$,28-dihydroxy-olean-12-enyl palmitate (4). White wax; $\mathrm{MS}(\mathrm{m} / \mathrm{z}): 662\left(4, \mathrm{C}_{46} \mathrm{H}_{80} \mathrm{O}_{2}-\mathrm{H}_{2} \mathrm{O}\right), 425$ (3), 218 (13), 203 (100), 189 (12). ${ }^{13} \mathrm{C} \mathrm{NMR}\left(\mathrm{CDCl}_{3}\right): \delta 38.1(\mathrm{C}-$ 1), 23.4 (C-2), 80.4 (C-3), 37.6 (C-4), 55.1 (C-5), 18.1 (C-6), 32.4 (C-7), 39.7 (C-8), 47.3 (C-9), 36.8 (C-10), 23.4 (C-11), 122.1 (C-12), 144.1 (C-13), 41.6 (C-14), 25.4 (C-15), 25.8 (C-16), 31.8 (C-17), 42.2 (C-18), 46.3 (C-19), 34.0 (C-20), 30.9 (C-21), 38.1 (C-22), 27.9 (C-23), 16.6 (C-24), 15.4 (C25), 16.6 (C-26), 25.8 (C-27), 69.7 (C-28), 33.1 (C-29), 23.5 (C-30), 173.6 (-COO-), $14.0\left(\mathrm{CH}_{3}\right), 29.7\left(\mathrm{CH}_{2}\right)_{\mathrm{n}} ;{ }^{1} \mathrm{HNMR}(300$ $\left.\mathrm{MHz} \mathrm{CDCl}_{3}\right): \delta 5.18$ (t, $J$ indt., $\mathrm{H}-12$ ); 4.50 (m, H-3), 3.55 (d, J $11 \mathrm{~Hz}, \mathrm{H}-28) ; 3.21$ (d, J $11 \mathrm{~Hz}, \mathrm{H}-28) ; 1.30$ (s, $\mathrm{CH}_{3}$ ); $1.17\left(\mathrm{~s}, \mathrm{CH}_{3}\right) ; 0.96\left(\mathrm{~s}, \mathrm{CH}_{3}\right), 0.94\left(\mathrm{~s}, \mathrm{CH}_{3}\right) ; 0.90\left(\mathrm{~s}, \mathrm{CH}_{3}\right) ; 0.87$ $\left(\mathrm{s}, \mathrm{CH}_{3}\right)$; and $0.86\left(\mathrm{~s}, \mathrm{CH}_{3}\right)$. IR $v_{\max } / \mathrm{cm}^{-1}: 3445,2926,2855$, 1733, 1464, 1379, 1250, 1179, 1095, 1046 (film).

$3 \beta$-hydroxy-11,12-epoxy-friedoolean-14-enyl palmitate (5). White wax; MS m/z: $678\left(8, \mathrm{C}_{46} \mathrm{H}_{80} \mathrm{O}_{3}\right), 423$ (25), 301 (15), 286 (29), 255 (31). $\left.{ }^{13} \mathrm{C} \mathrm{NMR} \mathrm{(} \mathrm{CDCl}_{3}\right)$ : Table; ${ }^{1} \mathrm{H}$ NMR $\left(300 \mathrm{MHz}, \mathrm{CDCl}_{3}\right): \delta 5.55(\mathrm{dd}, J 7.9$ and $3.3 \mathrm{~Hz}$, $\mathrm{H}-15) ; 4.52$ (dd, $J 11.0$ and $4.8 \mathrm{~Hz}, \mathrm{H}-3$ ); 3.11 (t, $J 4.8 \mathrm{~Hz}$, H-11), 2.80 (d, J 4.8 Hz, H-12); 1.10 (s, $\mathrm{CH}_{3}$ ); 1.08 (s, 2 
$\left.\mathrm{CH}_{3}\right) ; 1.00\left(\mathrm{~s}, \mathrm{CH}_{3}\right), 0.97\left(\mathrm{~s}, \mathrm{CH}_{3}\right) ; 0.87\left(\mathrm{~s}, \mathrm{CH}_{3}\right) ; 0.83$ (s, $\left.\mathrm{CH}_{3}\right)$. IR $v_{\max } / \mathrm{cm}^{-1}: 2920,2852,1731,1249,987,720$ (film).

Methyl palmitate; Oil; GC-MS, EIMS $\mathrm{m} / \mathrm{z}$ (rel. int.): $270[\mathrm{M}]^{+}$(22), 214 (5), 227 (18), 213 (5), 199 (10), 185 (10), 171(10), 157 (5), 143 (21), 129 (8), 115 (5), 101 (8), 87 (69), 74 (100), 55 (45).

\section{Acknowledgments}

The authors are grateful to CNPq (Conselho Nacional de Desenvolvimento Científico e Tecnológico) for grants and to CNPq and CAPES for fellowships support.

\section{References}

1. Evans, W. C.; J. Ethnopharmacol. 1981, 3, 265.

2. Hegnauer, R.; J. Ethnopharmacol. 1981, 3, 279.

3. Plowman, T.; Fieldiana: Botany - New Series 1987, 19 Publication 1373 .
4. Chávez, J. P.; Dos Santos, I. D.; Cruz, F. G.; David, J. M.; Phytochemistry 1996, 41, 941.

5. Mahato, S. B.; Kundu, A. P.; Phytochemistry 1994, 37, 1517.

6. Kagawa, M.; Minami, H.; Nakahara, M.; Takahashi, H.; Takada, S.; Fukuyama, Y.; Phytochemistry 1998, 47, 1101.

7. Ikuta, A.; Morikawa, A.; J. Nat. Prod. 1992, 55, 1230.

8. Mathias, L.; Vieira, I. J. C.; Braz-Filho, R.; Rodrigues Filho, E.; J. Braz. Chem. Soc. 2000, 11, 195.

9. Tanaka, R.; Matsunaga, S.; Phytochemistry 1988, 27, 3579.

10. Barnes, R. A.; Pereira, A. L.; Scofield, T. C. V.; Braz-Filho, R.; Pinto, A. C.; Chem. Pharm. Bull. 1984, 32, 3674.

11. Ito, K., Lai, J.; Chem. Pharm. Bull. 1978, 26, 1908.

12. Mendes, C. C.; Cruz, F. G.; David, J. M.; Nascimento, I. P.; David, J. P.; Quim. Nova 1999, 22, 185.

13. Carbonell, S. A.; Aquino Neto, F. R.; Cardoso, J. N.; Pereira, A. dos S.; Amaral, A. C.; Barnes, R. A.; J. Chromatogr. Sci. 2000, $38,234$.

Received: April 17, 2001 Published on the web: September 26, 2002 